\section{Simultaneous tromboembolic events in a patient with heterozygous MTHFR mutation}

\section{Abstract}

Background: Hyperhomocysteinemia is a well recognised risk factor for arterial and venous thrombosis. The most common form results from methylenetetrahydrofolate reductase (MTHFR) gene mutations leading to decreased enzymatic activity.

Case report: We present the case of a 34 year-old woman with a sudden onset of left hemiparesis and aphasia accompanied by retrosternal pain. She is diagnosed with acute posteroinferolateral myocardial infarction and stroke. Homocysteine level was determined and it was moderately elevated. The coronary angiogram revealed partially recanalised embolic occlusion of posterior left ventricular branch and posterior interventricular artery. A conservative treatment management is adopted. She remained haemodynamically stable, with complete resolution of neurological symptoms and evolution to subacute myocardial infarction.

Conclusions: The particularity of our case is represented by symultaneous thromboembolic events causing myocardial infarction and ischemic stroke in a patient with a history of recurrent pregnancy loss, which was previously diagnosed with MTHFR gene mutation. Moderate hyperhomocysteinemia, also found in our patient, is recognised as an ethiopathogenic factor of thrombophilia. The right diagnosis and therapeutic approach could be the key to improved prognosis in this category of patients. MTHFR gene mutation causing hyperhomocysteinemia should be suspected in patients with thromboembolic events, especially when occuring repeatedly or at young ages.
L. Macovei ${ }^{1,2}$, Alexandra Gurzu², D.M Alexandrescu², Catalina Arsenescu Georgescu $^{1,2}$

1 Grigore T. Popa. University of Medicine and Pharmacy.

2 George I.M. Georgescu. Cardiovascular Disease Institute - Cardiology, lasi, Romania.

Contact information:

Liviu Macovei.

Đ liviughemacovei@yahoo.com

\section{Keywords}

Tromboembolic Events, Heterozygous MTHFR Mutation, Stroke 


\section{Introduction}

Thrombophilias are conditions associated with hypercoagulable status and increased risk of arterial and venous thrombosis, which represents a significant cause of mortality and morbidity worldwide [1]. The prothrombotic states may be inherited or acquired, but also due to genetic and environmental interactions [2]. Investigating for thrombophilia requires an initial evaluation of classical prothrombotic risk factors such as smoking, dyslipidemias, arterial hypertension or diabetes mellitus. Extended profile of investigations is necessary in patients with arterial or venous thrombosis which occur repeateadly, in unusual sites or at young ages, when family aggregation of thrombotic events is identified, as well as in women with recurrent idiopathic pregnancy loss. It must include a complete blood count and erythrocyte sedimentation rate, a blood film examination, prothrombin time (PT) and activated partial thromboplastin time (aPTT), factor $V$ Leiden, antithrombin and fibrinogen levels, protein $C$ and $S$, prothrombin gene mutations, homocysteinemia, methylenetetrahydrofolate reductase (MTHFR) gene mutations and antiphospholipid antibodies [3].

Homocysteine has been recognised as a cardiovascular risk factor besides the traditional ones such as smoking, obesity, diabetes mellitus and arterial hypertension, in line with the observations made in patients with homocystinuria [4-6]. This is an inborn error of methionine metabolism caused by deficient activity of cysthationine $\beta$-synthase (CBS) and thereby impairment of the transsulphuration pathway leading to excessive accumulation of homocysteine $[7,8]$. Numerous studies have demostrated the early onset and rapid development of arteriosclerosis in patients with homocystinuria. Moreover, thromboembolic events, both arterial and venous have been reported, which represent the main life threatening complication at young ages [4, 8-11].

Experimental data suggested the mechanisms responsible for atherogenic and thrombogenic effects of high homocysteine levels: induces oxidative stress and vascular inflammation, promotes endotelial dysfunction as a result of increased asymmetric dimethylarginine (ADMA), an endogenous inhibitor of NO-syntase, reduces bioavailability of nitric oxide, alters lipoprotein metabolism, produces vascular hypertrophy in the microcirculation, stimulates tissue factor expression in monocytes, increases platelet aggregation and interferes with several clotting factors [12-16]. A new study demonstrated that hyperhomocysteinemia exacerbates vascular constrictive remodelling after arterial balloon injury by accelerated neointima formation and collagen accumulation in the adventitia [17].

Homocysteine concentrations are determined by synergistic action of genetic and nutritional factors such as serum folate, riboflavin and cobalamin [1820]. It appears to be also influenced by physiological factors (dietary habits, male sex, menopause, alcohol and coffee intake, smoking, increased muscle mass), diseases (reduced glomerular filtration rate and overt renal failure, hypothyroidism, diabetes mellitus, psoriasis) and drugs [16, 20].

Methylenetetrahydrofolate reductase (MTHFR) is involved in homocysteine metabolism and catalyzes the conversion of 5,10-methylenetetrahydrofolate (5,10 MTHF) to 5-methyltetrahydrofolate. This serves as a methyl donor in the subsequent homocysteine remethylation to methionine, reaction catalyzed by methionine synthase (MS) and requiring cobalamin as a cofactor [21]. It is also acknowledged that MTHFR plays a role in distributing folate species either towards homocysteine remthylation as depicted above, or to nucleic acids biosynthesis [21, 22]. Two common MTHFR gene polymorphisms have been identified: C677T and A1298C. C677T polymorphism results from $C \rightarrow T$ transition at nucleotide 677 in exon 4 and produces an alanine to valine amino acid substitution in the biomolecular structure $[23,24]$. The incidence of homozygous mutation (TT) in general population varies between 5 and 12\% [25-28]. The heterozygous mutation has an incindence of $25-40 \%$ 
[29]. The C677T mutation produces a thermolabile variant of the enzyme characterized by decreased catalytic activity and hyperhomocysteinemia. In comparison with the wild type allele, the residual enzyme activity is as low as 30 to $50 \%$ in homozygotes and 65\% in heterozygotes [30-32].

\section{Case report}

We present the case of a female patient from urban environment, aged 34, with a remote smoking history of 5 pack-years, who reported no drinking or drug use and without significant family history. The patient's medical history was notable for obstetrical events consisting of two pregnancies (at age 29 and 31) that ended at an unknown gestational age and the reason was not determined. Eighteen months ago she had a stillbirth occuring in a fullterm pregnancy. Shortly after she was tested for thrombophilia and the heterozygous C677T mutation of MTHFR gene was discovered. At the time treatment with aspirin, folic acid and omega 3 fatty acids was recommended, but the patient interrupted it after two months.

The patient had been well until the day of admission, when she reported sudden onset of left hemiparesis and motor aphasia, strongly suggestive of right hemisphere stroke. Non-contrast computed tomography was performed within 2 hours from presentation and showed no images consis- tent with intracerebral infarction or hemorrhage. Shortly after the investigation and before starting anticoagulant therapy the patient reported sudden development of retrosternal pain of medium intensity, occuring at rest and lasting longer than 30 minutes. The electrocardiogram showed ST segment elevation and Q waves in inferior leads and correlated with raised myocardial biomarkers (creatine-kinase MB 166 u/L, TroponinT 7.72 ng/ mL, ASAT 288 u/L, LDH 1438U/L). She was referred to a cardiologist.

On examination the patient is haemodynamically stable, blood pressure (BP) $120 / 70 \mathrm{mmHg}$ at both arms, heart rate (HR) 80, rhythmic heart sounds without additional murmurs and normal oxygen saturation. The neurological examination revealed minimal motor deficit, paresthesia and weakness of the left arm and no aphasia. The ECG aspect is consistent with the diagnosis of acute posteroinferolateral myocardial infarction with ST segment elevation (Fig.1). Ecocardiography revealed undilated left ventricle with preserved global systolic function, with an ejection fraction of $50 \%$, normal contractility except for akinesia of the mediobasal segment of the inferior wall. There are no signs of pericardial effusion, intracavitary thrombi, atrial dilation, diastolic dysfunction, valvular disease or pulmonary hypertension and the right ventricle is normal.

Figure 1: Acute posteroinferolateral ST elevation myocardial infarction.
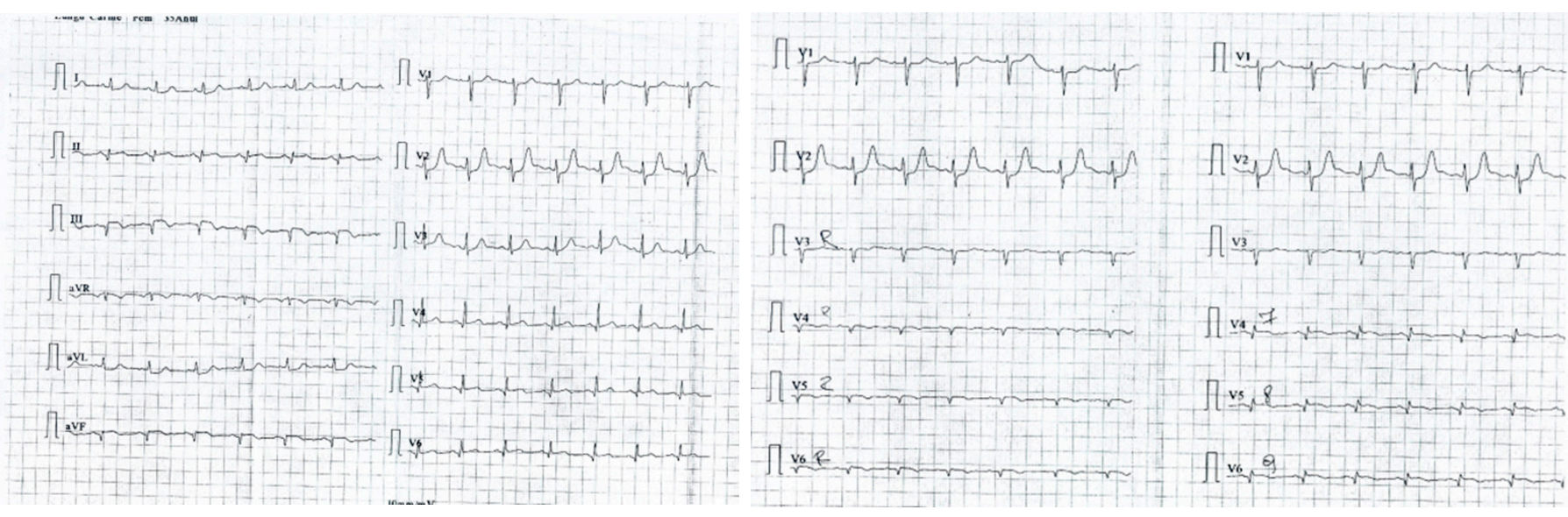
The patient underwent emergency coronary angiography for non-ST-segment elevation myocardial infarction which revealed partially recanalised embolic occlusion of posterior left ventricular branch and posterior interventricular artery (Fig.2). A conservative treatment strategy is adopted and anticoagulant therapy with unfractioned heparin is immediately started. Dual antiplatelet therapy (aspirin plus clopidogrel) and high-dose statin (atorvastatin) are associated. Spironolactone is added later on and is preferred as anti-remodelling agent due to low blood pressure values.

Figure 2: Partially recanalised embolic occlusion of posterior left ventricular branch and posterior interventricular artery.

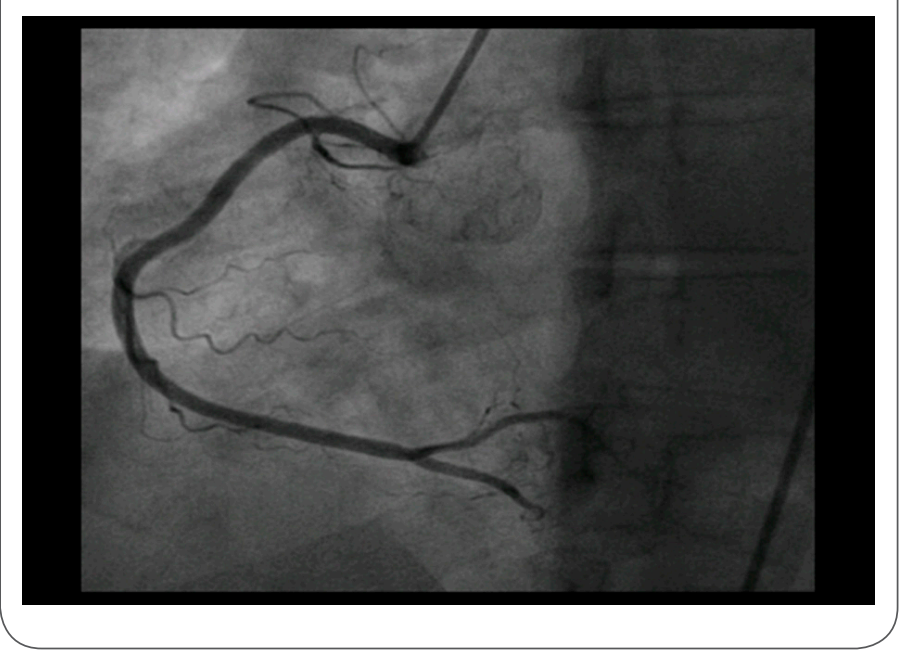

A new computed tomography of the brain is performed in the fifth day after admission. It revealed a cortico-subcortical hypodense area, 40/29mm, located in the temporo-parietal right hemisphere, suggestive of subacute ischemic stroke.

Further testing for thrombophilia was recommended in order to rule out causes of acquired prothrombotic states. The titres of antinuclear antibodies and their subsets, as well as antiphospholipid antibodies were within the normal range. Homocysteine plasma concentration has also been determined and it was moderately raised (32 $\mathrm{mmol} / \mathrm{L}$ ).

Under treatment she remained haemodynamically stable, experienced no recurrent anginal pain and had a complete resolution of neurological symptoms within three days from admission. Repeated ECG showed evolution to subacute myocardial infarction aspect and transthoracic echocardiogram at discharge revealed a slight improvement of inferior wall contractility with residual hipokinesis of the medio-basal segment. The patient is discharged home after 12 days of hospitalization with the main diagnosis of acute posteroinferolateral myocardial infarction with conservative treatment and acute temporo-parietal ischemic stroke, both due to thromboembolic events in the context of thrombophilia.

\section{Discussion}

The mechanism by which MTHFR gene mutations produce prothrombotic states is represented by eleveted levels of plasma homocysteine due to decreasd enzymatic activity of methylenetetrahydrofolate reductase. This effect is amplified by all the above mentioned factors, especially low concentrations of serum folate and vitamins B complex. However, data from literature are inconsistent and insufficient.

Numerous studies have demonstrated an increase in cardiovascular risk in the presence of elevated levels of homocysteine [30-35]. Discordant results have been found in prospective studies, some of them showing strong associations and some of them none [35]. A meta-analysis of 30 prospective and retrospective studies showed that $25 \%$ lower homocysteine levels was associated with $11 \%$ lower ischemic heart disease risk and $19 \%$ lower stroke risk, suggesting an independent role of homocysteine as a cardiovascular risk factor, albeit modest [36]. Another meta-analysis demonstrated a weak, but significant association between homocysteinemia and coronary heart disease risk in prospective studies and a more robust association when correlated with cerebrovascular disease [37]. 
Data drom literature indicate the association between moderately raised homocysteinemia and atherothrombosis risk, nevertheless in our patient no underlying atherosclerotic lesions have been found, pointing out a thromboembolic mechanism, both for stroke and myocardial infarction.

Medical data strongly affirm the association of severe hyperhomocysteinemia with high cardiovascular risk. However, regarding moderate or mild elevations in homocysteine levels, determined most frequently by MTHFR gene mutations, the results of the studies are discordant [38-46]. In this case, simultaneous ischemic events occured in a patient with no overt classical risk factors. Although moderately elevated, hyperhomocysteinemia due to MTHFR mutation, previously identified in this patient, has been responsible for concurrent thromboembolic stroke and myocardial infarction.

There is debate about the existence of a real causal relationship between hyperhomocysteinemia per se and the cardiovascular outcomes. Although most of the studies demonstrate the association, little evidence is available to support the direct causality, relationship [44, 47, 48]. Albeit several pathogenic effects of hyperhomocysteinemia have been evidenced, the following uncertainties emerged: is hyperhomocysteinemia merely associated with classical risk factors like smoking, dyslipidemias, arterial hypertension, thus creating confusion regarding its independent role in atherogenesis and thrombogenesis; is hyperhomocysteinemia an effect of atherosclerosis and/or acute vascular events rather than a causative agent [47-50]; the existence of subclinical premature renal impairment in atherosclerosis patients, thereby affecting homocysteine clearance $[47,49,51]$. Therefore it has been postulated that homocysteine is at most a marker of cardiovascular risk rather than an ethiological factor. Studying the correlation between MTHFR genotypes and cardiovascular risk has been proposed in order to demonstrate that a cause of chronic hyperhomocysteinemia is associated implicitly with high cardiovascular risk, therefore supporting the direct causality relationship $[44,47]$.

MTHFR gene mutation carriers have a decreased enzymatic activity and higher levels of homocysteine which are inversely related to folate status. A meta-analysis including 40 studies, both retrospective and prospective, demonstrated a $16 \%$ higher risk of developing coronary heart disease in patients with MTHFR 677TT genotype and a trend toward increased risk in heterozygous patients (CT genotype) compared the normal genotype (CC). It also showed that the risk is high only in patients with low folate status [44]. Significant higher risk of ischemic heart disease, deep vein thrombosis and stroke associated with $\mathrm{MTH}$ FR-TT genotype has been found in another metaanalysis including 92 studies, concluding that this correlation provides evidence for direct causality between hyperhomocysteinemia and cardiovascular disease [38].

Recurrent pregnancy loss represents a health issue affecting up to $5 \%$ of women of reproductive age [52]. The ethiological factors include uterine anomalies, endocrinologic disorders such as hypothyroidism, chromosomial or immunologic abnormalities and infectious diseases [53-55]. After ruling out the above mentioned factors, thrombophilia may be the underlying pathology in women with recurrent miscarriages [54, 55]. Adverse pregnancy outcomes reportedly associated with thrombophilia are preeclampsia, abruptio placentae, IUGR-intrauterine growth restriction, IUFDintrauterine fetal demise and stillbirth [56]. There is debate as to whether MTHFR mutations are associated with pregnancy complications and data are inconsistent. Placental vasculopathy, seemingly determined by hyperhomocysteinemia, has been proposed as ethiopathogenic mechanism [57]. The term encompasses the abnormal placental findings at anatomopathological examination and develop 
as a result of endotelial dysfunction, vasoconstriction, hypercoagulability and thrombosis, placentar ischaemia and infarction, all leading to impaired placentar perfusion and compromising the materno-fetal circulation [58-61]. Our patient has a history of three pregnacy losses, including stillbirth, without any identified cause except for MTHFR gene mutation causing hyperhomocysteinemia and prothrombotic state, which was not reversed by anticoagulant therapy during pregnancy.

\section{Conclusions}

The particularity of the presented case is the occurance of two simultaneous thromboembolic events, coronary and cerebrovascular, in the presence of moderate hyperhomocysteinemia most likely due to MTHFR gene mutation. This adds to the evidence pleeding for significant association of hyperhomocysteinemia with prothrombotic state leading to increased cardiovascular risk. MTHFR gene mutations, as the main causes of moderate high levels of homocysteine, should be suspected in patients with thromboembolic events and no classical risk factors. Recurrent pregnancy loss is another manifestation of thrombophilia caused by hyperhomocysteinemia and MTHFR gene mutations. Correct and timely diagnosis of thrombophilia in patients with a first embolic event or pregnancy loss, followed by adequate therapeutic management could result in improved prognosis for this category of patients.

\section{References}

1. Khan S, Dickerman JD. Hereditary thrombophilia. Thromb J 2006; 4: 15

2. Rosendaal FR. Venous thrombosis: a multicausal disease. Lancet 1999; 353(9159): 1167-73

3. Hoffbrand AV, Moss P.A.H. Essential Haematology. 6th ed. Oxford:Wiley Blackwell 2011, p363-71
4. Mudd SH, Skovby F, Levy HL, Pettigrew KD, Wilcken B, Pyeritz RE, Andria G, Boers GHJ, Mromberg IL, Cerone R, Fowler B, Grobe $H$, Schmidt $H$, Schweitzer L. The natural history of homocystinuria due to cysthationine b-synthase deficiency. Am J Hum Genet 1985; 37: 1-31

5. Skovby F, Gaustadnes M, Mudd SH. A revisit to the natural history of homocystinuria due to cystathionine $\beta$-synthase deficiency. Mol Genet Metab 2010; 99:1-3

6. van den Berg M, Boers GH. Homocystinuria: what about mild hyperhomocysteinaemia? Postgrad Med J 1996; 72: 513-8

7. Finkelstein JD, Mudd SH, Irreverre F, Laster L. Homocystinuria due to cystathionine synthetase deficiency: the mode of inheritance. Science. 1964; 146: 785-7

8. Kluijtmans LAJ, van den Heuvel LPWJ, Boers GHJ, et al. Molecular genetic analysis in mild hyperhomocysteinemia: a common mutation in the methylenetetrahydrofolate reductase gene is a genetic risk factor for cardiovascular disease. Am. J. Hum. Genet1996; 58: 35-41

9. McCully KS. Vascular pathology of homocysteinemia: implications for the pathogenesis of arteriosclerosis. Am J Pathol 1969; 56: 111-128

10. Mudd SH, Levy HL, Skovby F. Disorders of transsulfuration. In: Scriver CR, Beaudet AL, Sly WS, Valle D, eds. The Metabolic and Molecular Bases of Inherited Disease. 7th ed. New York, NY: McGraw-Hill 1995: 1279-1327

11. Boers GHJ (1986) Homocystinuria: a risk factor of premature vascular disease. Clinical research series no 3. Holland/Riverton, Dordrecht

12. Hankey GJ, Eikelboom JW. Homocysteine and vascular disease. Lancet 1999; 354: 407-413

13. Symons JD, Mullick AE, Ensunsa JL, et al. Hyperhomocysteinaemia evoked by folate depletion: effects on coronary and carotid arterial function. Arterioscler Thromb Vasc Biol 2002; 22: 772780

14. Faraci FM. Hyperhomocysteinaemia: a million ways to lose control. Arterioscler Thromb Vasc Biol 2003; 23: 371-373

15. Faraci FM, Lentz SR. Hyperhomocysteinemia, oxidative stress, and cerebral vascular dysfunction. Stroke 2004; 35: 345-347

16. Hankey GJ, Eikelboom JW, Ho WK, van Bockxmeer FM. Clinical usefulness of plasma homocysteine in vascular disease. Med J Aust 2004; 181:314-318

17. Guo YH, Chen FY, Wang GS, Chen L, Gao W. Diet-induced hyperhomocysteinemia exacerbates vascular reverse remodelling of balloon-injured arteries in rat. Chin Med J (Engl) 2008; 121: 2265-71

18. Hustad, S. et al. Riboflavin as a determinant of plasma total homocysteine: effect modification by the methylenetetrahydrofolate reductase C677T polymorphism. Clin. Chem 2000; 46, 1065-1071 
19. D'Angelo, A. et al. The role of vitamin B12 in fasting hyperhomocysteinemia and its interaction with the homozygous C677T mutation of the methylenetetrahydrofolate reductase (MTHFR) gene. Acase-control study of patients with earlyonset thrombotic events. Thromb. Haemost 2000; 83, 563-570

20. Schneede J, Refsum H, and Ueland PM . Biological and environmental determinants of plasma homocysteine. Semin Thromb Hemost 2000; 26: 263-279

21. Ueland PM, Hustad S, Schneede J, Refsum H, Vollset SE. Biological and clinical implications of the MTHFR C677T polymorphism. Trends Pharmacol Sci. 2001; 22195-201

22. Bailey, L.B. and Gregory, J.F. III. Polymorphisms of methylenetetrahydrofolate reductase and other enzymes: metabolic significance, risks and impact on folate requirement. J. Nutr 1999, 129, 919-922

23. Isotalo P, Wells GA, Donnelly JG. Neonatal and fetal methylenetetrahydrofolate reductase genetic polymorphisms: an examination of C677T and A1298C mutations. Am J Hum Genet 2000; 67: 986-90

24. Schneider JA, Rees DC, Liu YT, et al. Worldwide distribution distribution of a common methylenetetrahydrofolate reductase mutation.(Letter). Am J Hum Genet 1998; 62: 1258-60

25. Deloughery TG, Evans A, Sadeghi A, et al. Common mutation in methylenetetrahydrofolate reductase: correlation with homocysteine metabolism and late-onset vascular disease. Circulation 1996; 94: 3074-3078

26. Frosst P, Blom HJ, Milos R, Goyette P, Sheppard CA, Matthews $R G$, Denheijer M, Kluijtmans LAJ, Vandenheuvel LP, Rozen R. A candidate genetic risk factor for vascular disease: a common mutation in methylenetetrahydrofolate reductase. Nat Genet 1995; 10: 111-113

27. Van der Put NMJ, Steegers-Theunissen RPM, Frosst $P$, Trijbels FJM, Eskes TKAB, van den Heuvel LP, Mariman CM, den Heyer $\mathrm{M}$, Rozen R, Blom HJ. Mutated methylene-tetrahydrofolate reductase as a risk factor for spina bifida. Lancet 1995; 346: 1070-1071

28. Kluijtmans LAJ, Vandenheuvel LPWJ, Boers GHJ, Frosst P, Stevens EMB, Denheijer M, Trijbels FJM, Rozen R, Blom HJ. Molecular genetic analysis in mild hyperhomocysteinemia: a common mutation in the methylenetetrahydrofolate reductase gene is a genetic risk factor for cardiovascular disease. Am J Hum Genet 1996; 58: 35-41

29. van der Put NMJ, Eskes TKAB, Blom HJ. Is the common $677 \mathrm{C}$ $T$ mutation in the methylenetetrahydrofolate reductase gene a risk factor for neural tube defects? A meta-analysis. Q. J. Med 1997; 90: 111

30. Gilbody S, Lewis S, Lightfoot T. Methylenetetrahydrofolate reductase (MTHFR) genetic polymorphisms and psychiatric disorders: a HuGE review. Am J Epidemiol 2007; 165: 1-13

31. Rozen R. Molecular genetics of methylenetetrahydrofolate reductase deficiency. J Inherit Metab Dis 1996; 19: 589-94.3
32. Kang S-S, Wong PWK, Susmano A, Sora J, Norusis M, Ruggie N. Thermolabile methylenetetrahydrofolate reductase: an inherited risk factor for coronary artery disease. AmJ Hum Genet 1991; 48: $536-545$

33. Clarke R, Daly L \& Robinson K et al. Hyperhomocysteinemia: An independent risk factor for vascular disease. N Engl J Med 1991; 324 17: 1149-1155

34. Boushey CJ, Beresford SA, Omenn GS \& Motulsky AG. A quantitative assessment of plasma homocysteine as a risk factor for vascular disease. Probable benefits of increasing folic acid intakes. JAMA 1995; 274 13: 1049-1057

35. Danesh J \& Lewington S. Plasma homocysteine and coronary heart disease: Systematic review of published epidemiological studies. J Cardiovasc Risk 1998; 5 4: 229-232

36. Homocysteine Studies Collaboration. Homocysteine and risk of ischemic heart disease and stroke: a meta-analysis. JAMA 2002; 288: 2015-222

37.Ford ES, Smith SJ, Stroup DF, Steinberg KK, Mueller PW, Thacker SB. Homocyst(e)ine and cardiovascular disease: a systematic review of the evidence with special emphasis on case-control studies and nested case-control studies. Int J Epidemiol 2002; 31: $59-70$

38. Wald DS, Law M, Morris JK. Homocysteine and cardiovascular disease: evidence on causality from a meta-analysis. BMJ 2002; 325: 1202

39. Brattstrom L, Wilcken DEL, Ohrvik J, Brudin L. Common methylene tetrahydrofolate reductase gene mutation leads to hyperhomocysteinemia but not to vascular disease. Circulation 1998; 98: 2520-6.

40. Kluijtmans LAJ, Kastelein JJP, Lindemans J, Boers GH, Heil SG, Bruschke $A V$, et al. Thermolabile methylenetetrahydrofolate reductase in coronary artery disease. Circulation 1997; 96: 2573-7

41. Jee SH, Beaty $\mathrm{TH}$, Suh I, Yoon $Y$, Appel LJ. The methylenetetra-hydrofolate reductase gene is associated with increased cardiovascular risk in Japan, but not in other populations. Atherosclerosis 2000;153:161-8

42. Wald DS, Morris JK, Law M, Wald NJ (2006) Folic acid, homocysteine and cardiovascular disease: judging causality in the face of inconclusive trial evidence. BMJ 333: 1114-7

43. Miller ER, Juraschek S, Pastor-Barriuso R, Bazzano LA, Appel LJ, et al. (2010) Meta-analysis of Folic acid Supplementation Trials on Risk of Cardiovascular Disease and Risk Interaction with Baseline Homocysteine levels. Am J Cardiol 106: 517-527

44. Klerk, M. et al. MTHFR 677CRT polymorphism and risk of coronary heart disease: a meta-analysis. J. Am. Med. Assoc 2002; 288, 2023-2031

45. Wald DS, Morris JK,Wald NJ. Reconciling the evidence on serum homocysteine and ischaemic heart disease: a meta-analysis. PLoS One 2011; 2: e16473 
46. Lewis SJ, Ebrahim S, Davey Smith G. Meta-analysis of MTHFR 677C->T polymorphism and coronary heart disease: does totality of evidence support causal role for homocysteine and preventive potential of folate? BMJ 2005; 331(7524): 1053

47.Brattstrom L, Wilcken DE. Homocysteine and cardiovascular disease: cause or effect? Am J Clin Nutr 2000; 72: 315-323

48. Cleophas TJ, Hornstra N, van Hoogstraten B, and van der MJ. Homocysteine, a risk factor for coronary artery disease or not? A meta-analysis. Am J Cardiol 2000; 86: 1005-1009

49. Clarke R, Lewington $S$, and Landray M. Homocysteine, renal function, and risk of cardiovascular disease. Kidney Int Suppl 2003; 84: S131-S133

50. Dudman NPB. An alternative view of homocysteine. Lancet 1999; 354: 2072-2074

51. Landray MJ, Baigent C: Renal function: An emerging risk factor for cardiovascular disease? Evidence-based Cardiovasc Med 2001; 5: 32-33

52. Sarig G, Younis JS, Hoffman R, Lanir N, Blumenfeld Z, Brenner B. Thrombophilia is common in women with idiopathic pregnancy loss and is associated with late pregnancy wastage. Fertil Steril 2002; 77: 342-347

53. Teremmahi Ardestani M, Nodushan HH, Aflatoonian A, Ghasemi $\mathrm{N}$, Sheikhha MH. Case control study of the factor $\mathrm{V}$ Leiden and factor II G20210A mutation frequency in women with recurrent pregnancy loss. Iran J Reprod Med 2013; 11: 61-4

54. Martínez-Zamora MÁ, Cervera R, Balasch J. Recurrent miscarriage, antiphospholipid antibodies and the risk of thromboembolic disease. Clin Rev Allergy Immunol 2012; 43: 265-74

55. Incebiyik, Adnan, et al. Prevalence of thromogenic gene mutations in women with recurrent miscarriage: A retrospective study of 1,507 patients. Obstetrics \& gynecology science 2014; 57.6: $513-517$

56. Kupferminc MJ, Thrombophilia and pregnancy. Reprod Biol Endocrinol 2003; 1: 111-66

57.Altomare I, Adler A, Aledort LM: The 5, 10 methylenetetrahydrofolate reductase C677T mutation and risk of fetal loss: a case series and review of the literature. Thromb J 2007; 5:17

58. van der Molen EF, Arends GE, Nelen WL, van der Put NJ, Heil SG, Eskes TK, et al. A common mutation in the 5,10-methylenetetrahydrofolate reductase gene as a new risk factor for placental vasculopathy. Am J Obstet Gynecol 2000; 182: $1258-63$

59. Salafia CM, Pezzullo JC, Lopez-Zeno JA, Simmens S, Minior VK,Vintzileos AM. Placental pathologic features of preterm preeclampsia. Am J Obstet Gynecol 1995; 173: 1097-105
60. Salafia CM, Minior VK, Pezzullo JC, Popek EJ, Rosenkrantz TS, Vintzileos AM. Intrauterine growth restriction in infants of less than thirty-two weeks' gestation: associated placental pathologic features. Am J Obstet Gynecol 1995; 173: 1049-57

61. Many A, Schreiber L, Rosner S, Lessing JB, Eldor A, Kupferminc MJ. Pathologic features of the placenta in women with severe pregnancy complications and thrombophilia. Obstet Gynecol 2001; 98: 1041-1044

\section{Comment on this article:}

\section{(f) $[$ in $8+\mathbf{S}$ P}

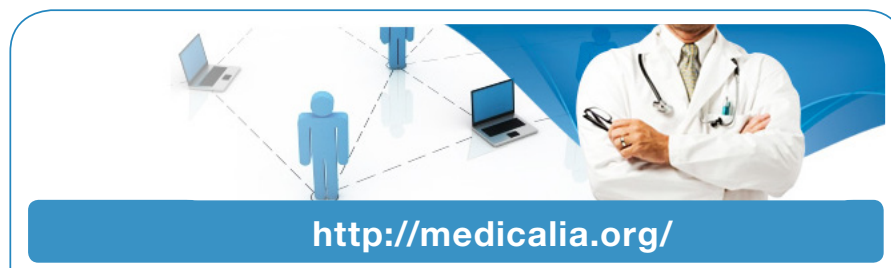

Where Doctors exchange clinical experiences, review their cases and share clinical knowledge. You can also access lots of medical publications for free. Join Now!

\section{Publish with iMedPub}

\section{http://www.imed.pub}

International Archives of Medicine is an open access journal publishing articles encompassing all aspects of medical science and clinical practice. IAM is considered a megajournal with independent sections on all areas of medicine. IAM is a really international journal with authors and board members from all around the world. The journal is widely indexed and classified Q1 in category Medicine. 